\title{
COVID-19 pandemic: an online-based survey of knowledge, perception, and adherence to preventive measures among educated Nigerian adults
}

\author{
Oyetunde T. Oyeyemi ${ }^{1}$ (D) Victoria O. Oladoyin ${ }^{2} \cdot$ Oluyemi A. Okunlola $^{3} \cdot$ Akinola Mosobalaje $^{4}$. \\ Ifeoluwa T. Oyeyemi ${ }^{1}$ - Wasiu O. Adebimpe ${ }^{2} \cdot$ Roseangela I. Nwuba $^{1} \cdot$ Iyadunni I. Anuoluwa $^{1}$ - Adebisi M. Tiamiyu ${ }^{1}$. \\ Oghale O. Ovuakporie-uvo ${ }^{1}$. Isaac A. Adesina ${ }^{1}$ • Babawale P. Olatunji ${ }^{1}$. Jennifer K. Kone ${ }^{1} \cdot$ Yinka D. Oluwafemi $^{1}$. \\ Caleb O. Obajaja ${ }^{1} \cdot$ Abiodun A. Ajiboye $^{1,5}$
}

Received: 17 July 2020 / Accepted: 3 December 2020 / Published online: 7 January 2021

(C) The Author(s), under exclusive licence to Springer-Verlag GmbH, DE part of Springer Nature 2021

\begin{abstract}
Aims One of the ways to manage the current coronavirus disease 2019 (COVID-19) pandemic is to monitor the public knowledge, risk perceptions, adherence to preventive measures, and level of preparedness behaviors. This is important in resourcelimited countries. This study determined the knowledge and perception regarding COVID-19; adherence to COVID-19 preventive measures; as well as predictors of self-perceived risk of contracting COVID-19 among Nigerian adults.

Methods A cross-sectional study was conducted among Nigerian adults $\geq 18$ years using an online survey. A convenience sampling method was utilized to recruit a total of 1022 study participants. The participants were recruited using the authors' social media networks. Data were analyzed using descriptive and inferential statistics at a 5\% level of statistical significance.

Results Generally, a high proportion of respondents had correct knowledge about COVID-19. However, only approximately half (49.8\% and 49.9\%) had correct knowledge that obesity was a risk factor for COVID-19 and that antibiotics cannot be used to treat COVID-19. Most (84.1\%) did not have a self-perceived risk of contracting COVID-19. Most (81.0\%) have been avoiding crowded places and $61.3 \%$ washed their hands frequently. Predictors of self-perceived risk of COVID-19 were age 40-59 years (OR 2.05, CI 1.217-3.435), $\geq 60$ years (OR 4.68, CI 1.888-11.583), and visiting crowded places (OR 2.27, CI 1.499-3.448).

Conclusion Our study recommends more rigorous public health education aimed at improving COVID-19 outbreak response in Nigeria. In addition, physical and social distancing should be emphasized across all age groups with additional focus on the older population.
\end{abstract}

Keywords Coronavirus disease $2019 \cdot$ Pandemic $\cdot$ Risk perception $\cdot$ Transmission control $\cdot$ Nigeria

Oyetunde T. Oyeyemi

ooyeyemi@unimed.edu.ng

1 Department of Biological Sciences, University of Medical Sciences, Ondo, Ondo State, Nigeria

2 Department of Community Medicine, University of Medical Sciences, Ondo, Ondo State, Nigeria

3 Department of Mathematics, University of Medical Sciences, Ondo, Ondo State, Nigeria

4 Department of Mathematics, Obafemi Awolowo University (ACE), Ondo, Ondo State, Nigeria

5 Department of Plant Science and Biotechnology, Federal University, Oye-Ekiti, Ekiti State, Nigeria

\section{Introduction}

Coronavirus disease 2019 (COVID-19) has been a major public health concern since December 2019 when it was first detected in Wuhan, China. The causal virus called the severe acute respiratory syndrome coronavirus 2 (SARS-CoV-2) is highly infectious and the disease has recorded more than 19 million cases within the space of approximately eight months of the outbreak. As of August 5, 2020, 215 countries of the world (Worldometer 2020) have been affected by the highly infectious SARS-CoV-2 and it still has a high chance of reaching many new territories. The global mortality rate was pegged at approximately $3.76 \%$ in early August 2020 (Worldometer 2020), but a shift from this is expected to occur before the end of the pandemic. 
Coronavirus disease 2019 was first confirmed in Nigeria on February 27, 2020, in Lagos State. The index case was an Italian who traveled from Italy to Nigeria (Maclean and Dahir 2020). On March 9, 2020, a Nigerian who had contact with the Italian was confirmed the second person infected with SARS-CoV-2. Nigeria ranked 3 rd in the total number of active COVID-19 cases in Africa as of August 4, 2020. As of the time of this report, there were 44,433 confirmed cases, from which 31,851 and 910 have recovered and died, respectively (Worldometer 2020). To curtail the spread of SARS-CoV-2 in Nigeria, a total lockdown was first imposed on two states (Lagos and Ogun states) and the Federal Capital Territory (FCT), while others were subjected to a partial lockdown. However, as at the time of this report, the lockdown has been relaxed for the recovery of the economy.

Coronavirus disease 2019 has become a major issue in Nigeria as cases have been confirmed in all 36 states of the country, including the FCT (Nigeria Centre for Disease Control 2020). From an epidemiological point of view, the observed trend in the incidence of newly confirmed cases in Nigeria suggests that it may take a while before the country can flatten the COVID-19 incidence curve. Due to the lack of a vaccine or proven drugs for the management of the disease, transmission control becomes a very important intervention that can abate the spread of the disease in the community and health care settings ( $\mathrm{Li}$ et al. 2020). This is even more important in a country that is deficient in a good public health care system. Despite the efforts put in place by the Nigerian government to mitigate the impact of COVID-19, poor public knowledge, attitudes, and practices of people relative to COVID-19 control can mar even the best national public health response.

Nigeria is currently in the heat of the COVID-19 pandemic, and to guarantee a successful early containment of the disease, in the absence of a vaccine, adherence to control measures determined by peoples' knowledge, attitudes, and practices toward COVID-19 is very important (Zhong et al. 2020). The aim of this study therefore was to determine the knowledge and perception of COVID-19 among educated Nigerian adults during a period when Nigeria is experiencing a consistent increase in the number of new cases. This study also assessed the adherence of Nigerian adults to the current COVID-19 preventive measure guidelines in Nigeria. Lastly, this study determined the predictors of selfperceived risk of contracting COVID-19 among the study participants. Findings from this study would provide useful information for public health policy development and implementation for quick response to the COVID-19 outbreak in Nigeria.

\section{Materials and methods}

\section{Study area}

The study was carried out in Nigeria, the most populated country in Africa. The country's population was estimated to be approximately 206 million in 2019 (World Population Prospects 2019). Nigeria is located on latitude $10^{\circ}$ North and longitude $8^{\circ}$ East and has a total area of $923,768 \mathrm{~km}^{2}$. According to the World Bank, approximately $49 \%$ of the population live in rural areas, and $51 \%$ in urban areas in 2019 (World Bank 2020). As at the time of this study, it was estimated that Nigeria had 96.05 million internet users amounting to $46.6 \%$ of the population (Clement 2020). The literacy rate among the Nigerian adult population was $62.02 \%$ in 2018 (UNESCO http://uis.unesco.org/en/country/ng).

\section{Study design and sample size}

This cross-sectional study was conducted from March 31 to April 25,2020 . To avoid physical contact with our participants, a convenience sampling method was utilized to recruit the study participants. We used the research team's social media networks (WhatsApp, Facebook, Twitter, and Instagram) and emails to source information via an online-based survey. The participants resided predominantly in urban and peri-urban communities. Only adults (age 18 years and above) were recruited for the study. Nigerians in the diaspora, foreigners living in Nigeria, and medical practitioners were excluded from the study. COVID-19 transmission is still on-going; thus, we had no prevalence data that could be used for the estimation of the sample size. Therefore, the minimum sample size was calculated based on the country's estimated 100 million adults population in 2019 (World Population Prospects 2019) and a $4 \%$ precision using an online-based sample size estimator (https://www.checkmarket.com/sample-size-calculator). A 95\% confidence level was used for the sample size estimation. Although a sample size of 601 participants was computed, all those who volunteered to participate in the study were included. Overall, we recruited 1258 participants for the study, but only 1022 had data that were fit for analysis. The study precision improved to approximately $3 \%$ when the inflated sample size of 1022 was used.

\section{Data collection}

Data was collected using a structured questionnaire adapted from the National Health Commission of the People's Republic of China protocols and guidelines on COVID19 (National Health Commission of the People's Republic of China 2020a, b). The questionnaire comprised four sections, namely socio-demographics, knowledge about COVID-19, perceptions about COVID-19, and adherence to preventive measures. 
Section one of the questionnaire comprised 10 questions on the socio-demographic characteristics of the participants. Information such as age, gender, educational level, religion, and marital status were obtained in this section. In section two, 26 questions related to knowledge about transmission, risk factors, symptoms, disease progression, treatment, and prevention of COVID-19 were asked. The third section had questions related to the perception of the respondents about COVID-19. The final section contained 12 questions on adherence to preventive measures against COVID-19.

\section{Ethical approval}

The study protocol was approved by the Ethics Committee of the University of Medical Sciences/Teaching Hospital, Ondo City, Ondo State, Nigeria. Careful explanation of the purpose, content, and implication of the research was made known to the participants. Confidentiality of the information provided was assured.

\section{Statistical analysis}

Data generated were checked for accuracy and coded. Subsequently, the data were then exported to SPSS version 24 (SPSS, Chicago, IL) for statistical analysis. Descriptive statistics such as frequency counts, percentages, and means were used to present responses that emanated from the survey. Chi-square test was used to determine bivariate associations between the dependent variable and selected sociodemographic features such as age, gender, marital status, and occupation of respondents; knowledge; perception; and preventive measures on COVID-19. Logistic regression analysis was used to determine the predictors of self-perceived risk of contracting COVID-19 among subjects recruited for the study. Variables on socio-demographic characteristics, knowledge, perception, and preventive measures on COVID-19 were included in the model. The statistical level of significance was set at $P<0.05$.

\section{Results}

The mean age of the participants was $33.4 \pm 11.8$ years, $53.5 \%$ were males, and $52.2 \%$ were not married. The majority $(88.5 \%)$ of the participants had education up to the tertiary level and approximately two-fifth (40.3\%) were civil servants (Table 1).

Most of the respondents had encountered information about the mode of transmission $(94.1 \%)$ and prevention (91.4\%) of COVID-19. The internet was the most $(97.0 \%)$ frequently reported source of information about the disease (Table 2).
Table 1 Sociodemographic characteristics of the respondents

\begin{tabular}{|c|c|c|}
\hline Variables & Frequency $(N=1022)$ & Percentage $(\%)$ \\
\hline \multicolumn{3}{|l|}{ Age (years) } \\
\hline $18-39$ & 756 & 74.0 \\
\hline $40-59$ & 230 & 22.5 \\
\hline$\geq 60$ & 36 & 3.5 \\
\hline \multicolumn{3}{|l|}{ Gender } \\
\hline Male & 547 & 53.5 \\
\hline Female & 475 & 46.5 \\
\hline \multicolumn{3}{|l|}{ Marital status } \\
\hline Married & 489 & 47.8 \\
\hline Not married & 533 & 52.2 \\
\hline \multicolumn{3}{|l|}{ Education } \\
\hline Tertiary & 904 & 88.5 \\
\hline Senior secondary & 112 & 11.0 \\
\hline Primary & 6 & 0.6 \\
\hline \multicolumn{3}{|l|}{ Religion } \\
\hline Christianity & 956 & 93.5 \\
\hline Islam & 56 & 5.5 \\
\hline Others & 10 & 1.0 \\
\hline \multicolumn{3}{|l|}{ Occupation } \\
\hline Trading & 101 & 9.9 \\
\hline Civil servant & 412 & 40.3 \\
\hline Farming & 21 & 2.1 \\
\hline Self-employed & 6 & 0.6 \\
\hline Student & 241 & 23.6 \\
\hline Unemployed & 79 & 7.7 \\
\hline Others & 162 & 15.9 \\
\hline
\end{tabular}

Correct knowledge about the mode of transmission, risk factors, symptoms, disease progression, treatment, and prevention of COVID-19 was generally high among the study participants. A high proportion (80.4\%) of the respondents correctly reported that chronic diseases were a risk factor for severe COVID-19, but only $49.8 \%$ knew that obesity was a risk factor for severe COVID-19. Although a higher proportion of the respondents correctly knew that cough $(95.3 \%)$ and fever $(89.3 \%$ ) were symptoms of COVID-19, only a few correctly knew that fatigue (47.4\%) and muscle pain (30.9\%) were also symptoms of the disease. Less than half $(46.0 \%)$ knew that persons infected with SARS-CoV-2 had reduced occurrence of common cold-associated symptoms such as stuffy nose, runny nose, and sneezing. Quite a number $(86.3 \%)$ of the respondents knew that not all persons infected with SARS-CoV-2 progressed to the severe form of COVID19 and $70.5 \%$ knew that most people infected with SARSCoV-2 will not die of the disease. Even though almost all the participants (94.7\%) correctly reported that there was currently no effective cure but early management of COVID-19 could aid recovery, $50.1 \%$ still wrongly stated that antibiotics 
Table 2 COVID-19 information which respondents have heard about

\begin{tabular}{lll}
\hline Variables & Frequency $(\mathrm{N}=1022)$ & Percentage (\%) \\
\hline Information domain* & & \\
Transmission & 962 & 94.1 \\
Prevention & 934 & 91.4 \\
Management & 668 & 65.4 \\
People at risk & 774 & 75.7 \\
Others & 40 & 3.9 \\
Frequency of hearing about COVID-19 & \\
Very often & 810 & 79.3 \\
Often & 158 & 15.5 \\
Sometimes & 41 & 4.0 \\
Never & 13 & 1.3 \\
Sources of information* & & \\
Internet & 991 & 97.0 \\
Radio & 545 & 53.3 \\
Television & 797 & 78.0 \\
Health centers & 205 & 20.1 \\
Friends & 593 & 58.0 \\
Community members & 270 & 26.4 \\
Church & 416 & 40.7 \\
Mosque & 35 & 3.4 \\
Others & 31 & 3.0 \\
\hline
\end{tabular}

*Multiple response

Others (information domain); conspiracy theories, benefit of good hygienic practices, data and statistics, death rate, economic impacts, genotypic mutation, convalescent plasma therapy, pathophysiology, diagnosis, morphology

Others (sources of information); WHO, NCDC, UNICEF, newspaper, place of work, university led webinar, seminar/training, books, family members

can be used to treat COVID-19. More than $90 \%$ of the participants knew that avoidance of crowded places, staying at home during transmission, and regular hand washing with soap under running tap could prevent COVID-19 transmission (Table 3).

A total of $98.5 \%$ agreed that the outbreak of COVID-19 in Nigeria was real, while about a tenth $(8.4 \%)$ perceived it as a disease of the rich people. Although $54.1 \%$ of the respondents perceived that the government of Nigeria is not handling the COVID-19 outbreak well, most (95.8\%) still believed the government will win the battle against the COVID-19 outbreak in Nigeria (Table 4).

Only a few, $15.9 \%$, believed they were at risk of contracting COVID-19. The commonly adduced reasons for not being at risk of contracting COVID-19 among those who did not perceive themselves to be at risk of contracting COVID-19 were they always avoided crowded places $(69.1 \%)$ and always washed their hands with soap under a running tap (67.1\%) (Table 5).
This study showed that $19 \%$ of the respondents had visited crowded places recently, $38.7 \%$ did not wash their hands with soap under running water very often, $37 \%$ rarely or never used hand sanitizers, and $64 \%$ did not wear face masks. The majority $(87.5 \%)$ of the respondents complied with the 'stay at home' government's policy to arrest the spread of COVID-19 (Table 6).

Factors that were significantly associated with selfperceived risk of contracting COVID-19 were age, gender, marital status, occupation, frequency of hearing about COVID-19, visitation to crowded places, use of hand sanitizers, compliance with a stay at home instruction from the government, and history of self-treatment with preventive drugs against COVID-19 $(P<0.05)$ (Table 7). Respondents who were 60 years and above were approximately five times more likely to perceive themselves as having a risk to contract the disease (OR 4.68, CI 1.888-11.583) compared to respondents aged 18-39 years. Female respondents were 0.5 times less likely to perceive themselves as having a risk to contract COVID-19 (OR 0.51, CI 0.352-0.751) when compared to male respondents. Respondents who were married were 0.5 times less likely to perceive themselves as having a risk to contract COVID-19 (OR 0.53, CI 0.321-0.888) compared to those who were not married. Visitation to crowded places was three times more likely to predict the self-perceived risk of contracting COVID-19 (OR 2.27, CI 1.499-3.448) compared to not visiting crowded places (Table 7).

\section{Discussion}

To the best of our knowledge, this is the first comprehensive report in Nigeria that considered the knowledge about the spread, symptoms, disease progression, risk factors, treatment, and preventive measures against COVID-19. Also, our study assessed perceptions about COVID-19 and adherence to preventive measures among the Nigerian population. We also determined the predictors of self-perceived risk of contracting COVID-19.

A common source of information about COVID-19 in this study was the internet. This is similar to what was reported in a recent study from Egypt, which also identified the internet as the most common source of information about COVID-19 (Abdelhafez et al. 2020). The use of the internet, however, has also increased the influx of fake and unauthenticated news. Caution should therefore be exercised in the use of online outlets as the major source of information by individuals. Doubtful online information should be verified from other reliable sources.

The knowledge about the spread, symptoms, disease progression, risk factors, treatment, and preventive measures against COVID-19 in this study was generally good. This can be attributable to the high level of education of our 
Table 3 Knowledge about COVID-19 $(\mathrm{N}=1022)$

Variables

Correct Percentage

response

(\%)

Eating or contact with wild animals could result in infection with COVID-19

$312 \quad 30.5$

COVID-19 spreads via respiratory droplets of infected individuals when they sneeze or cough

$999 \quad 97.7$

No transmission of COVID-19 without fever or other symptoms

$723 \quad 70.7$

Money can serve as vehicle of COVID-19 transmission

$839 \quad 82.1$

Older people are more likely to have severe COVID-19

$912 \quad 89.2$

Chronic illnesses is associated with severe COVID-19

$822 \quad 80.4$

Non-obese condition is associated with severe COVID-19

509

49.8

Symptoms of COVID-19

Fever

913

484

89.3

Fatigue

Cough

Muscle pain

Sneezing

Persons infected with COVID-19 have lower frequency in occurrence of common cold-associated symptoms

Not all persons with COVID-19 will develop severe cases of the disease

Most people infected with COVID-19 die from it

No effective cure for COVID-19 but early management of infection can aid recovery

Antibiotics can be used to treat COVID-19

Wearing of face mask can protect against infection with COVID-19

Children and young adults need not take measures to prevent against COVID-19 because the disease is more severe among old adults

Avoidance of crowded places is necessary for COVID-19 prevention

974

47.4

95.3

$316 \quad 30.9$

$889 \quad 87.0$

$470 \quad 46.0$

$882 \quad 86.3$

$720 \quad 70.5$

$968 \quad 94.7$

$510 \quad 49.9$

$852 \quad 83.4$

$878 \quad 85.9$

$1004 \quad 98.2$

$949 \quad 92.9$

$1003 \quad 98.1$

$1007 \quad 98.5$

$989 \quad 96.8$

$1004 \quad 98.2$

$999 \quad 97.7$

$975 \quad 97.4$

The observation period during isolation of people who are infected with COVID-19 is 14 days

*Multiple response

respondents as corroborated by a study among educated people in China, which also revealed good knowledge about COVID-19 (Zhong et al. 2020). However, quite a number of our study's participants misconstrued sneezing as a symptom of COVID-19. This deviates from recent studies in Saudi Arabia and Malaysia, where the participants showed better knowledge in differentiating between common cold-related symptoms from those of COVID-19 (Al-Hanawi et al. 2020; Azlan et al. 2020). Although unprotected sneezing is one of the effective ways of transmitting the novel coronavirus from an infected individual, sneezing is not part of the community case definitions for COVID-19 according to NCDC guidelines. More public enlightenment on the community case definitions of COVID-19 is needed to avoid the stigma associated with sneezing in public places that are increasingly becoming high in Nigeria.
The approximately $20 \%$ and $50 \%$ of respondents who had lack of knowledge about the relationship between COVID-19 and chronic illnesses and obesity, respectively, is disturbing, as there is documented evidence that older individuals with chronic illnesses and obesity need to take extra precaution to prevent themselves from contracting COVID-19 because they are more at risk of suffering from COVID-19-related complications (Guan et al. 2020; Zhou et al. 2020).

Another call for concern is the reasonable number of respondents who believed that antibiotics can be used for managing COVID-19 and those who did not know that antibiotics cannot be used for managing COVID-19. These two groups of individuals could become victims of inappropriate use of antibiotics.

The observation that some individuals believed that COVID-19 is a disease of the rich is disturbing. This set of 
Table 4 Perceptions about COVID-19

\begin{tabular}{|c|c|c|}
\hline Variables & Frequency $(\mathrm{N}=1022)$ & Percentage $(\%)$ \\
\hline \multicolumn{3}{|c|}{ COVID-19 outbreak in Nigeria is real } \\
\hline Strongly agree & 740 & 72.4 \\
\hline Agree & 267 & 26.1 \\
\hline Disagree & 7 & 0.7 \\
\hline Strongly disagree & 8 & 0.8 \\
\hline \multicolumn{3}{|c|}{ COVID-19 is a disease of the rich people } \\
\hline Strongly agree & 26 & 2.5 \\
\hline Agree & 60 & 5.9 \\
\hline Disagree & 458 & 44.8 \\
\hline Strongly disagree & 478 & 46.8 \\
\hline \multicolumn{3}{|c|}{$\begin{array}{l}\text { Total lockdown of the nation will help to control the spread of } \\
\text { COVID-19 }\end{array}$} \\
\hline Strongly agree & 541 & 52.9 \\
\hline Agree & 405 & 39.6 \\
\hline Disagree & 63 & 6.2 \\
\hline Strongly disagree & 13 & 1.3 \\
\hline \multicolumn{3}{|c|}{$\begin{array}{l}\text { Compliance with preventive measures will curtail the spread of } \\
\text { COVID-19 over time }\end{array}$} \\
\hline Strongly agree & 683 & 66.8 \\
\hline Agree & 324 & 31.7 \\
\hline Disagree & 12 & 1.2 \\
\hline Strongly disagree & 3 & 0.3 \\
\hline \multicolumn{3}{|c|}{$\begin{array}{l}\text { The Nigerian government is handling the problem with COVID-19 } \\
\text { well }\end{array}$} \\
\hline Strongly agree & 72 & 7.0 \\
\hline Agree & 481 & 47.1 \\
\hline Disagree & 352 & 34.4 \\
\hline Strongly disagree & 117 & 11.4 \\
\hline \multicolumn{3}{|c|}{ I have confidence that Nigeria can win the battle against COVID-19 } \\
\hline Strongly agree & 569 & 55.7 \\
\hline Agree & 410 & 40.1 \\
\hline Disagree & 35 & 3.4 \\
\hline Strongly disagree & 8 & 0.8 \\
\hline
\end{tabular}

individuals are not likely to adhere to the COVID-19 prevention guidelines and this may mar the current efforts targeted against this highly contagious disease. Findings from this study revealed that our study participants are quite optimistic that the Nigerian government can win the current battle against COVID-19. Study participants from recent studies among Saudi Arabia and Chinese populations also showed similar optimism (Al-Hanawi et al. 2020; Zhong et al. 2020). The previous Nigerian government response to the Ebola outbreak may be a possible reason why the participants are confident that the government can handle the current COVID-19 outbreak.

Even though our respondents reported adherence to some precautionary measures to prevent the spread of COVID-19, the adherence in our study was lower compared to the measures taken in other countries such as China and Egypt (Abdelhafez et al. 2020; Zhong et al. 2020). The lower adherence reported in our study was largely due to the inability of the participants to afford hand sanitizers and its scarcity. Others felt its use was not necessary. The use of a face mask by a few of our respondents was consistent with the observation recorded in Ethiopia (Akalu et al. 2020). The Centers for Disease Control and Prevention (CDC) has recommended the use of face masks in areas where there is significant community transmission of COVID-19 (CDC 2020). The WHO also recommended the use of face masks for the population at risk of exposure and the vulnerable groups (WHO 2020). In Nigeria, where there is no efficient public health alert system, reliable disinfection program, and increase in the transmission rates in many major cities, the government and the local public health agencies of the country have made the right decision in enforcing the wearing of face masks in public places.

The use of vitamins was the most common preventive chemotherapy used by our respondents. Although an earlier study supported the use of vitamins for the management of COVID19 (Lee et al. 2020), a more recent review of the evidence on
Table 5 Self-perceived risk of contracting COVID-19

\begin{tabular}{lll}
\hline Variables & $\begin{array}{l}\text { Frequency } \\
(\mathrm{N}=1022)\end{array}$ & $\begin{array}{l}\text { Percentage } \\
(\%)\end{array}$ \\
\hline Self-perceived risk of contracting COVID-19 & 859 & 84.1 \\
No & 163 & 15.9 \\
Yes & & \\
Reasons for not being at risk of contracting COVID-19* & 706 & 69.1 \\
I always avoid crowded places & 688 & 67.3 \\
I wash my hands always with soap under running tap & 42 & 4.1 \\
I always take chloroquine, herbs, and other medications as preventive & & 47.6 \\
$\quad$ measures & 486 & 21.3 \\
I always use hand sanitizer & 218 & 12.0 \\
I always use face mask whenever I go out & 123 & \\
Others
\end{tabular}


Table 6 Adherence to COVID19 preventive measures

\begin{tabular}{|c|c|c|}
\hline Variables & Frequency & Percentage $(\%)$ \\
\hline \multicolumn{3}{|l|}{ Visitation to crowded place in recent times } \\
\hline Yes & 194 & 19.0 \\
\hline No & 828 & 81.0 \\
\hline \multicolumn{3}{|l|}{ Regular hand washing with soap and water under a running tap } \\
\hline Very often & 626 & 61.3 \\
\hline Often & 297 & 29.1 \\
\hline Sometimes & 92 & 9.0 \\
\hline Never & 7 & 0.7 \\
\hline \multicolumn{3}{|l|}{ Use of hand sanitizer } \\
\hline Always & 644 & 63.0 \\
\hline Rarely & 328 & 32.1 \\
\hline Never & 50 & 4.9 \\
\hline \multicolumn{3}{|l|}{ Reasons for a rare or non-usage of hand sanitizer } \\
\hline I cannot afford it & 101 & 9.9 \\
\hline I do not know where to buy it & 4 & 0.4 \\
\hline It is scarce to get & 105 & 10.3 \\
\hline It is not necessary & 103 & 10.1 \\
\hline Others & 65 & 6.4 \\
\hline \multicolumn{3}{|l|}{ Wearing of face mask when leaving home in recent times } \\
\hline Yes & 368 & 36.0 \\
\hline No & 654 & 64.0 \\
\hline \multicolumn{3}{|l|}{ Reasons for non-usage of face mask } \\
\hline I cannot afford it & 49 & 4.8 \\
\hline Price hike & 101 & 9.9 \\
\hline I do not know how to use it & 4 & 0.4 \\
\hline I do not know where to buy it & 50 & 4.9 \\
\hline It is not necessary & 334 & 32.7 \\
\hline I have been indoors & 90 & 8.8 \\
\hline Others & 26 & 2.5 \\
\hline \multicolumn{3}{|l|}{ Compliance with stay at home instruction from the government } \\
\hline Yes & 894 & 87.5 \\
\hline No & 128 & 12.5 \\
\hline \multicolumn{3}{|l|}{ Reasons for non-compliance with stay at home instructions } \\
\hline I earn daily income & 33 & 3.2 \\
\hline My employer is not releasing me from work & 25 & 2.4 \\
\hline I am on grade level 13 and above, so I have to go to work & 18 & 1.8 \\
\hline I have urgent matters to attend to & 31 & 3.0 \\
\hline I need to attend church or mosque & 2 & 0.2 \\
\hline Others & 19 & 1.9 \\
\hline \multicolumn{3}{|c|}{ History of self-treatment with perceived preventive drugs against COVID-19 since the outbreak } \\
\hline Yes & 288 & 28.2 \\
\hline No & 734 & 71.8 \\
\hline \multicolumn{3}{|c|}{ Common medications used for self-prevention against of COVID-19 } \\
\hline Chloroquine & 16 & 1.6 \\
\hline Antibiotics & 17 & 1.7 \\
\hline Vitamins & 220 & 21.5 \\
\hline Other & 35 & 3.4 \\
\hline
\end{tabular}


Table 7 Predictors of selfperceived risk of contracting COVID-19

\begin{tabular}{|c|c|c|c|c|c|}
\hline & \multicolumn{2}{|c|}{$\begin{array}{l}\text { Self-perceived risk of } \\
\text { contracting COVID-19 }\end{array}$} & \multirow[t]{2}{*}{$P$ value ${ }^{\dagger}$} & \multirow[t]{2}{*}{ Adjusted OR $(95 \% \mathrm{CI})$} & \multirow[t]{2}{*}{ Adjusted $P$ value ${ }^{\S}$} \\
\hline & Yes $(\%)$ & No (\%) & & & \\
\hline \multicolumn{6}{|l|}{ Age (years) } \\
\hline $18-39$ & 14.7 & 85.3 & \multirow[t]{3}{*}{0.111} & 1.00 (Reference) & \\
\hline $40-59$ & 18.7 & 81.3 & & $2.05(1.217-3.435)$ & $0.007 *$ \\
\hline$\geq 60$ & 25.0 & 75.0 & & $4.68(1.888-11.583)$ & $0.001 *$ \\
\hline \multicolumn{6}{|l|}{ Gender } \\
\hline Male & 19.7 & 80.3 & \multirow[t]{2}{*}{$<0.0001$} & 1.00 (Reference) & \\
\hline Female & 11.6 & 88.4 & & $0.51(0.352-0.751)$ & $0.001^{*}$ \\
\hline \multicolumn{6}{|l|}{ Marital status } \\
\hline Married & 14.9 & 85.1 & \multirow[t]{2}{*}{0.393} & $0.53(0.321-0.888)$ & \multirow[t]{2}{*}{$0.016^{*}$} \\
\hline Not married & 16.9 & 83.1 & & 1.00 (Reference) & \\
\hline \multicolumn{6}{|l|}{ Occupation } \\
\hline Trading & 18.8 & 81.2 & \multirow[t]{5}{*}{0.597} & $1.318(0.724-2.398)$ & \multirow[t]{2}{*}{0.366} \\
\hline Civil servant & 16.7 & 83.3 & & 1.00 (Reference) & \\
\hline Farming & 9.5 & 90.5 & & $0.360(0.078-1.662)$ & 0.191 \\
\hline Student & 16.6 & 83.4 & & $1.201(0.690-2.090)$ & 0.517 \\
\hline Others & 13.4 & 86.6 & & $0.700(0.425-1.155)$ & 0.163 \\
\hline \multicolumn{6}{|c|}{ Frequency of hearing about COVID-19 } \\
\hline Very often & 17.0 & 83.0 & \multirow[t]{3}{*}{0.159} & 1.00 (Reference) & \\
\hline Often & 13.3 & 86.7 & & $0.73(0.430-1.207)$ & 0.213 \\
\hline Sometimes/never & 9.8 & 90.2 & & $0.39(0.125-1.199)$ & 0.100 \\
\hline \multicolumn{6}{|c|}{ Visitation to crowded place in recent times } \\
\hline Yes & 24.2 & 75.8 & \multirow[t]{2}{*}{$<0.0001$} & $2.27(1.499-3.448)$ & \multirow[t]{2}{*}{$<0.001^{*}$} \\
\hline No & 14.0 & 86.0 & & 1.00 (Reference) & \\
\hline \multicolumn{6}{|c|}{ Regular hand washing with soap and water under a running tap } \\
\hline Very often & 13.8 & 86.1 & \multirow[t]{4}{*}{0.125} & 1.00 (Reference) & \\
\hline Often & 18.5 & 81.5 & & $1.25(0.835-1.863)$ & 0.280 \\
\hline Sometimes & 21.7 & 78.3 & & $1.69(0.926-3.096)$ & 0.087 \\
\hline Never & 14.3 & 85.7 & & $0.49(0.056-4.342)$ & 0.523 \\
\hline \multicolumn{6}{|c|}{ Use of hand sanitizer } \\
\hline Always & 16.6 & 83.4 & \multirow[t]{3}{*}{0.247} & 1.00 (Reference) & \\
\hline Rarely & 13.7 & 86.3 & & $0.70(0.466-1.058)$ & 0.091 \\
\hline Never & 22.0 & 78.0 & & $1.29(0.613-2.730)$ & 0.499 \\
\hline \multicolumn{6}{|c|}{ Compliance with stay at home instruction from the government } \\
\hline Yes & 15.2 & 84.8 & \multirow[t]{2}{*}{0.089} & 1.00 (Reference) & \\
\hline No & 21.1 & 78.9 & & $1.16(0.791-1.915)$ & 0.566 \\
\hline \multicolumn{6}{|c|}{ History of self-treatment with perceived preventive drugs against COVID-19 since the outbreak } \\
\hline Yes & 17.4 & 82.6 & 0.440 & $1.15(0.782-1.691)$ & 0.479 \\
\hline No & 15.4 & 84.6 & & 1.00 (Reference) & \\
\hline
\end{tabular}

${ }^{\dagger} P$ value in chi-square test; ${ }^{\dagger}$ Adjusted odds ratio in logistic regression (confidence interval); ${ }^{\S}$ Adjusted $P$ value in logistic regression; *Significant values

Others; Self-employed, unemployed the use of vitamin D for treatment or prevention in COVID-19 rebuffed this (Grant et al. 2020).

Older adults and those who visited crowded places were more likely to have a self-perceived risk of contracting
COVID-19 from our study. These are not surprising because documented risk factors for transmission of COVID-19 included older age and overcrowding. These results, therefore, underscores the importance of physical and social distancing 
across all age groups with additional focus on the older population. Females and married persons were less likely to have a self-perceived risk of contracting COVID-19. The reason why this was so remains unclear and more research may need to be conducted to determine the reason for this.

The limitation of this study was that the uneducated people and those living in rural areas who are likely to be more vulnerable due to poor knowledge and poor preventive measures practices were not represented in this study. It is therefore very important to conduct a similar study among the uneducated and rural dwellers in Nigeria. Also, the online nature of the study did not permit us to conduct a focus group discussion and in-depth interviews, which could have further provided us with more details on the participants' responses. Despite these limitations, this study was able to add to the existing body of knowledge on COVID-19 in Nigeria.

Currently, COVID-19 is being transmitted actively in Nigeria. To effectively break the chain of transmission of the current outbreak, there is an urgent need for robust public enlightenment regarding the disease. In addition, physical and social distancing should be emphasized across all age groups with additional focus on the older population. The use of a face mask should be enforced in public places to further prevent community transmission.

Authors contributions OTO - Conception, design, data collection, first manuscript draft; VOO - Design, data collection, extensive manuscript revision; OAO - Data analysis, manuscript revision; AM - online questionnaire design and curation; ITO, WOA, RIN, IAA, AMT, OOO, IAA, $\mathrm{BPO}, \mathrm{JKK}, \mathrm{YDO}, \mathrm{COO} \& \mathrm{AAA}$ - Data collection, manuscript revision. All authors approved the final manuscript draft.

Funding This study was not funded by any organization.

\section{Compliance with ethical standards}

Conflict of interest The authors declare no conflict of interest.

Ethical approval The study protocol was approved by the Ethics Committee of the University of Medical Sciences/Teaching Hospital, Ondo City, Ondo State, Nigeria.

Informed consent Not applicable.

\section{References}

Abdelhafez AS, Mohammed Z, Ibrahim ME, Ziady HH, Alorabi M, Ayyad M, Sultan EA (2020) Knowledge, perceptions, and attitude of Egyptians towards the novel coronavirus disease (COVID-19). J Comm Health 45:881-890. https://doi.org/10.1007/s10900-02000827-7

Akalu Y, Ayelign B, Molla MD (2020) Knowledge, attitude and practice towards COVID-19 among chronic disease patients at Addis Zemen hospital, Northwest Ethiopia. Infect Drug Resist 13:1949-1960. https://doi.org/10.2147/IDR.S258736
Al-Hanawi MK, Angawi K, Alshareef N, Qattan AMN, Helmy HZ, Abudawood Y, Alqurashi M, Kattan WM, Kadasah NA, Chirwa GC, Alsharqi O (2020) Knowledge, attitude and practice toward COVID-19 among the public in the Kingdom of Saudi Arabia: a cross-sectional study. Front Public Health 8:217. https://doi.org/10. 3389/fpubh.2020.00217

Azlan AA, Hamzah MR, Sern TJ, Ayub SH, Mohamad E (2020) Public knowledge, attitudes and practices towards COVID-19: a crosssectional study in Malaysia. PLoS One 15(5):e0233668. https:// doi.org/10.1371/journal.pone.0233668

Centers for Disease Control and Prevention (CDC) (2020) Recommendation regarding the use of cloth face coverings, especially in areas of significant community-based transmission. Retrieved April 4, 2020, from https://www.cdc.gov/ coronavirus/2019-ncov/prevent-getting-sick/cloth-face-cover. html

Clement J (2020) Nigeria: number of internet users 2015-2025. https:// www.statista.com/statistics/183849/internet-users-nigeria. Retrieved August 5, 2020

Grant WB, Lahore H, McDonnell SL, Baggerly CA, French CB, Aliano JL, Bhattoa HP et al (2020) Evidence that vitamin D supplementation could reduce risk of influenza and COVID-19 infections and deaths. Nutrients 12:988. https://doi.org/10.3390/nu12040988

Guan W, Ni Z, Hu Y, Liang W, Ou C, He J et al (2020) Clinical characteristics of coronavirus disease 2019 in China. N Engl J Med 382: 1708-1720 https://www.who.int/news-room/q-a-detail/q-acoronaviruses. Retrieved May 4, 2020

Lee J, van Hecke O, Roberts N (2020) Vitamin D: A rapid review of the evidence for treatment or prevention in COVID19. The Centre for Evidence-Based Medicine (CEBM), 2020. https://www.cebm.net/covid-19/vitamin-d-a-rapid-review-ofthe-evidence-for-treatment-or-prevention-in-covid-19. Retrieved May 5, 2020

Li YC, Bai WZ, Hashikawa T (2020) The neuroinvasive potential of SARS-CoV-2 may play a role in the respiratory failure of COVID19 patients. J Med Virol 92:552-555. https://doi.org/10.1002/jmv. 25728

Maclean R, Dahir A-L (2020) Nigeria responds to first coronavirus case in sub-Saharan Africa. The New York Times. https:// www.nytimes.com/2020/02/28/world/africa/nigeriacoronavirus.html Retrieved 10 March 2020

National Health Commission of the People's Republic of China (2020a) Protocol for community prevention and control of the 2019 novel coronavirus (2019-nCoV) infected pneumonia (trial version).http:// w w w. n h c.gov.c n/j k j/s $3577 / 202001 /$ dd1e502534004a8d88b6a10f329a3369.shtml. Retrieved May 5, 2020

National Health Commission of the People's Republic of China (2020b) Guideline for the diagnosis and treatment of 2019 novel coronavirus (2019-nCoV) infected pneumonia (The Third Trial Version). http:// w w w. n h c.gov.c n/y z y g j/s 7653 p/202001/ f492c9153ea9437bb587ce2ffc bee1fa.shtml. Retrieved May 5, 2020

Nigeria Centre for Disease Control (NCDC) (2020) COVID 19 Nigeria. https://covid19.ncdc.gov.ng. Retrieved August 5, 2020

World Bank (2020) https://data.worldbank.org. Retrieved August 6, 2020

World Health Organization (2020) Coronavirus disease (COVID-19) advice for the public: When and how to use masks. https:/www.who. int/emergencies/diseases/novel-coronavirus-2019/advice-forpublic/when-and-how-to-use-masks. Retrieved May 5, 2020

World Population Prospects. United Nations Department of Economic and Social Affairs Population Dynamics (2019) https://population. un.org/wpp/. Retrieved May 3, 2020

Worldometer (2020) COVID-19 Coronavirus pandemic. https://www. worldometers.info/coronavirus. Retrieved May 6, 2020 
Zhong B-L, Luo W, Li H-M, Zhang Q-Q, Liu X-G, Li W-T, Li Y (2020) Knowledge, attitudes, and practices towards COVID-19 among Chinese residents during the rapid rise period of the COVID-19 outbreak: a quick online cross-sectional survey. Int J Biol Sci 16: 45-1752. https://doi.org/10.7150/ijbs.45221

Zhou F, Yu T, Du R, Fan G, Liu Y, Liu Z et al (2020) Clinical course and risk factors for mortality of adult inpatients with COVID-19 in
Wuhan, China: a retrospective cohort study. Lancet 395:10541062. https://doi.org/10.1016/S0140-6736(20)30566-3

Publisher's note Springer Nature remains neutral with regard to jurisdictional claims in published maps and institutional affiliations. 